\title{
KSHV- and EBV-associated germinotropic lymphoproliferative disorder
}

Ming-Qing Du, Tim C. Diss, Hongxiang Liu, Hongtao Ye, Rifat A. Hamoudi, José Cabeçadas, Henry Y. Dong, Nancy Lee Harris, John K. C. Chan, John W. Rees, Ahmet Dogan, and Peter G. Isaacson

\begin{abstract}
Kaposi sarcoma-associated herpesvirus (KSHV) is known to be associated with 3 distinct lymphoproliferative disorders: primary effusion lymphoma (PEL), multicentric Castleman disease (MCD), and MCDassociated plasmablastic lymphoma. We report 3 cases of a previously undescribed KSHV-associated lymphoproliferative disorder. The disease presented as localized lymphadenopathy and showed a favorable response to chemotherapy or radiotherapy. Histologically, the lymphoproliferation is characterized by plasmablasts that preferentially in-
\end{abstract}

volved germinal centers of the lymphoid follicles, forming confluent aggregates. They were negative for CD20, CD27, CD79a, CD138, BCL6, and CD10 but showed monotypic $\kappa$ or $\lambda$ light chain. Clusters of $\mathrm{CD}_{10}{ }^{+} \mathrm{CD}_{20}{ }^{+}$residual follicle center cells were identified in some of the follicles. The plasmablasts were positive for both KSHV and EBV, and most of them also expressed viral interleukin-6 (vIL-6). Unexpectedly, molecular analysis of whole tissue sections or microdissected KSHV-positive aggregates demonstrated a polyclonal or oligoclonal pattern of im- munoglobulin (Ig) gene rearrangement. The plasmablasts showed somatic mutation and intraclonal variation in the rearranged Ig genes, and one case expressed switched Ig heavy chain $(\lg A)$, suggesting that they originated from germinal center B cells. We propose calling this distinctive entity "KSHV-associated germinotropic Iymphoproliferative disorder." (Blood. 2002;100:3415-3418)

(๑) 2002 by The American Society of Hematology

\section{Introduction}

Kaposi sarcoma-associated herpesvirus (KSHV) was initially identified from Kaposi sarcoma and plays a causative role in the genesis of this disease. ${ }^{1} \mathrm{KSHV}$ is distantly related to another human $\gamma$ herpesvirus, Epstein-Barr virus (EBV), and is also known as human herpesvirus 8 (HHV8). ${ }^{1}$ Like EBV, KSHV is lymphotropic and has been shown to be associated with 3 distinct lymphoproliferative disorders: primary effusion lymphoma (PEL), multicentric Castleman disease (MCD), and MCD-associated plasmablastic lymphoma. ${ }^{2}$

PEL occurs in patients with human immunodeficiency virus (HIV) infection and involves primarily body cavities and occasionally extranodal sites. ${ }^{3}$ The lymphoma is composed of KSHVpositive immunoblasts with plasmacytoid cytoplasm, which are also commonly coinfected by EBV. The tumor cells usually do not express immunoglobulin (Ig) and B-cell markers but express syndecan-1 (CD138) and harbor hypermutated rearranged immunoglobulin genes, suggesting that they originate from germinal center or postgerminal center B cells. ${ }^{3-5}$ In contrast, KSHV-associated MCD occurs in patients with and without HIV infection and mainly involves lymph nodes and spleen. ${ }^{6,7}$ In patients with MCD, KSHV induces a range of lymphoproliferative lesions-from polyclonal isolated plasmablasts in the mantle zone of B-cell follicles and microlymphoma to monoclonal microlymphoma and frank plasmablastic lymphoma. ${ }^{7}$ Irrespective of these different lesions, KSHVpositive plasmablasts are monotypic, expressing exclusively
$\operatorname{IgM} \lambda .^{6,7}$ They express high levels of cytoplasmic Ig and surface CD27, therefore resembling mature B cells. However, they originate from naive B cells: Their rearranged Ig genes lack somatic mutation. ${ }^{7}$ Both KSHV-associated PEL and MCD usually pursue an aggressive clinical course..$^{3,8}$

This report describes 3 cases of a previously undescribed KSHV-associated lymphoproliferative disorder characterized by plasmablasts that are coinfected by KSHV and EBV and preferentially involving the germinal centers of B-cell follicles.

\section{Study design}

\section{Case history}

The clinical features are summarized in Table 1. The patients presented with localized lymphadenopathy and were otherwise healthy. Two patients tested negative for HIV, and they showed a favorable response to chemotherapy or radiotherapy.

\section{Histology and immunohistochemistry}

Histologic sections of the lymph node biopsies were reviewed. Immunostaining for KSHV LNA-1 (LANA) encoded by viral open reading frame (ORF) 73 and viral interleukin-6 (vIL-6) was carried out with rat monoclonal antibody LN53 and a rabbit polyclonal antibody, respectively (Advanced Biotechnologies, Columbia, MD) as described previously. ${ }^{6,7}$ Consecutive sections were stained with antibodies to Ig heavy chains $\alpha, \delta, \gamma$, and $\mu$; light
From the Department of Histopathology, University College London, London, United Kingdom; Serviço de Anatomia Patológica, Instituto Português de Oncologia de Francisco Gentil, Lisbon, Portugal; Department of Pathology, Massachusetts General Hospital, Boston, MA; Department of Pathology, Queen Elizabeth Hospital, Hong Kong; and Department of Pathology, Dandenong Hospital, Victoria, Australia.

Submitted February 15, 2002; accepted April 15, 2002. Prepublished online as Blood First Edition Paper, July 5, 2002; DOI 10.1182/blood-2002-02-0487.

Supported by research grants from the Leukemia Research Fund and Cancer
Research Campaign.

Reprints: Ming-Qing Du, Department of Histopathology, Royal Free and University College Medical School, University College London, Rockefeller Bldg, University St, London WC1E 6JJ, United Kingdom; e-mail: m.du@ucl.ac.uk.

The publication costs of this article were defrayed in part by page charge payment. Therefore, and solely to indicate this fact, this article is hereby marked "advertisement" in accordance with 18 U.S.C. section 1734.

(C) 2002 by The American Society of Hematology 
Table 1. Clinical, histologic, immunophenotypic, and genotypic features of KSHV-associated GLD

\begin{tabular}{|c|c|c|c|}
\hline & Case 1 & Case 2 & Case 3 \\
\hline Age, y & 41 & 61 & 63 \\
\hline Sex & Male & Male & Female \\
\hline Clinical presentation & $\begin{array}{l}\text { Axillary }(6 \times 6 \times 6 \mathrm{~cm}) \text { and cervical lymph node } \\
\text { enlargement for } 6 \mathrm{y} \text {; staging revealed right perirenal } \\
\text { lymphadenopathy; bone marrow trephine and } \\
\text { aspirate were normal }\end{array}$ & $\begin{array}{l}\text { Submandibular and inguinal lymph node } \\
\text { enlargement for } 4 \text { y; staging showed slightly } \\
\text { enlarged spleen and right } \\
\text { "paratracheal" lymphadenopathy }\end{array}$ & $\begin{array}{l}\text { Presented with left leg swelling and } \\
\text { paraesthesia; enlarged paraaortic } \\
\text { lymph node }(5 \times 4 \times 3.5 \mathrm{~cm})\end{array}$ \\
\hline Viral serology & $\mathrm{KSHV}^{+}, \mathrm{EBV}^{+}, \mathrm{HCV}^{+}, \mathrm{HIV}^{-}$ & $\mathrm{KSHV}^{+}, \mathrm{EBV}^{+}, \mathrm{HIV}^{-}$ & Not available \\
\hline Treatment and outcome & 6 cycles of $\mathrm{CHOP}$, complete remission for $7 \mathrm{y}$ & $\begin{array}{l}\text { Surgical excision and radiotherapy, } \\
\text { complete remission for } 15 \mathrm{y}\end{array}$ & New case \\
\hline \multirow[t]{5}{*}{ B-cell markers } & $\mathrm{CD}^{2} 0^{-} \mathrm{CD}^{-} 7^{-}$ & $\mathrm{CD}_{20}^{-} \mathrm{CD}^{-} 7^{-}$ & $\mathrm{CD}^{2} 0^{-} \mathrm{CD}_{27}^{-}$ \\
\hline & $\mathrm{CD}^{-} 0^{-} \mathrm{CD}^{-} 8^{-}$ & $\mathrm{CD}^{+} 0^{+} \mathrm{CD} 8^{+}$ & $\mathrm{CD}^{-} 0^{-} \mathrm{CD} 8^{+}$ \\
\hline & $\mathrm{CD} 79 \mathrm{a}^{-} \mathrm{CD} 138^{-}$ & $\mathrm{CD} 9 \mathrm{a}^{-} \mathrm{CD} 138^{-}$ & $\mathrm{CD} 7 \mathrm{a}^{-} \mathrm{CD}^{-} 38^{-}$ \\
\hline & $\mathrm{BCL}^{-} \mathrm{CD}^{-} 0^{-}$ & $\mathrm{BCL6}^{-} \mathrm{CD}^{-} 0^{-}$ & $\mathrm{BCL6}^{-} \mathrm{CD}^{-} 0^{-}$ \\
\hline & & $\mathrm{EMA}^{-}$ & $\mathrm{BCL}^{-}$ \\
\hline Ig light chain & $\lambda$ & $\lambda$ & к \\
\hline Ig heavy chain & $\lg \mathrm{M}^{+} \mathrm{D}^{+}$ & $\lg \mathrm{A}^{+}$ & $\lg \mathrm{M}^{-}, \lg \mathrm{D}^{-}, \lg \mathrm{G}^{-}, \lg \mathrm{A}^{-}$ \\
\hline \multicolumn{4}{|l|}{ Clonality } \\
\hline Whole tissue section & Weak dominant band in a polyclonal background & PCR failed & Polyclonal \\
\hline KSHV-positive aggregate & Oligoclonal & PCR failed & Polyclonal \\
\hline $\mathrm{V}_{\mathrm{H}}$ gene mutation & Yes & Not done & Not done \\
\hline
\end{tabular}

CHOP indicates cyclophosphamide, hydroxydoxorubicin, oncovin, prednisone.

chains $\kappa$ and $\lambda$; and CD10, CD20, CD21, CD27, CD30, CD38, CD79a, CD138 (Dako, High Wycombe, United Kingdom), BCL2, BCL6 (PharMingen, San Diego, CA), and Ki67 (Dako, Cambridge, United Kingdom).

\section{DNA preparation and microdissection}

DNA samples were prepared from whole sections of formalin-fixed and paraffin-embedded tissues. To study KSHV-positive cells, sections of lymph nodes were first stained for LNA-1. Confluent KSHV-positive cells (1000-4000) from the same focus of consecutive sections were microdissected and pooled together. DNA was extracted as described previously. ${ }^{7,9}$

\section{PCR and sequence analysis of the rearranged lg genes}

To assess clonality, the rearranged Ig heavy chain and light chain (both $\mathrm{K}$ and $\lambda$ ) genes were amplified from the framework 3 (FR3) to the joining $(J)$ regions by polymerase chain reaction (PCR) as described previously. ${ }^{7,10}$ For analysis of somatic hypermutation in the rearranged Ig genes, the region from FR2 to the $\mathrm{J}$ segment was amplified. ${ }^{10} \mathrm{FR} 2-\mathrm{J}_{\mathrm{H}}$ PCR products were analyzed on $6 \%$ polyacrylamide gels, while $\mathrm{FR} 3-\mathrm{J}_{\mathrm{H}}$ products were examined on $10 \%$ polyacrylamide gels.

To study somatic mutation of the rearranged Ig genes, FR2-J $\mathrm{J}_{\mathrm{H}}$ PCR products were cloned and sequenced. ${ }^{7}$ The variable (V), diversity (D), and joining $(\mathrm{J})$ segments were identified by sequence comparison to the $\mathrm{V}$ BASE using online DNAPLOT (MRC Center for Protein Engineering)

\section{EBER in situ hybridization}

In situ hybridization was carried out with a PCR-generated DNA probe labeled with digoxigenin, followed by incubation with antidigoxingenin conjugated with alkaline phosphatase (Roche Diagnostics, East Sussex, United Kingdom) and visualization with BCIP (5-bromo-4-chloro-3-indoyl phosphate p-toluidine salt) and nitroblue tetrazolium (NBT) ${ }^{11}$

\section{Results and discussion}

All 3 cases presented as localized lymphadenopathy, and none had a history of Kaposi sarcoma, immunodeficiency, or immunosuppression. Two cases were treated by chemotherapy or radiotherapy and responded favorably, one in complete remission for 7 years and the other for 15 years.
Lymph node biopsies from all 3 cases showed similar histologic features. Overall architecture of the lymph node was preserved. In some of the follicles, the germinal centers were replaced partially or completely by large cells with a moderate amount of amphophilic cytoplasm and large eccentric vesicular nuclei containing 1 or 2 prominent nucleoli. Most of them were similar to the plasmablasts described in KSHV-associated MCD; others showed more bizarre anaplastic features (Figure 1A). These plasmablasts occurred as clusters and often coalesced to form confluent aggregates, comparable to the KSHV-positive microlymphomas in $\mathrm{MCD}$. Clusters of $\mathrm{CD} 10^{+} \mathrm{CD} 20^{+}$residual follicle center cells were identified in some of the involved follicles. Plasmablasts were found neither in the mantle zones, which appeared to be normal, nor in the interfollicular zone. However, mantle zone B cells were seen encroaching into the follicle centers in the involved follicles, reminiscent of progressive transformation of the germinal center. Uninvolved lymphoid follicles had reactive follicle centers and did not exhibit features of Castleman disease. The interfollicular zone showed prominent plasmacytosis.

All plasmablasts showed stippled nuclear staining for KSHV LNA-1 and were coinfected by EBV as revealed by EBV-encoded RNA (EBER) in situ hybridization (Figure 1A). Most KSHVpositive plasmablasts expressed vIL-6. They were $\mathrm{CD} 20^{-}, \mathrm{CD}^{-} 7^{-}$, $\mathrm{CD}^{+/-}, \mathrm{CD}^{+1} 8^{+/-}, \mathrm{CD}^{+} 9 \mathrm{a}^{-}, \mathrm{CD} 138^{-}, \mathrm{BCL6}^{-}, \mathrm{CD}^{-}{ }^{-}, \mathrm{BCL}^{-}$ and expressed monotypic $\mathrm{Ig}$ light chain, $\lambda$ in 2 cases and $\kappa$ in 1 (Figure 1A). Plasmablasts in cases 1 and 2 expressed IgM/D and $\operatorname{Ig} \mathrm{A}$, respectively (Figure $1 \mathrm{~A}$ ), while case 3 failed to show immunostaining for heavy chains. Most KSHV-positive plasmablasts were $\mathrm{Ki}^{+} 7^{+}$, indicating that they were in cell cycle. CD21 staining showed that KSHV-positive cells occurred within meshworks of follicular dendritic cells (Figure 1A).

Despite the expression of monotypic Ig light chain by KSHVpositive plasmablasts, FR3- $\mathrm{J}_{\mathrm{H}}$, FR3- $\mathrm{J}_{\mathrm{K}}$, and FR3- $\mathrm{J}_{\lambda}$ PCR of DNA samples from whole tissue sections showed a weak dominant band in a polyclonal background in case 1 but a polyclonal pattern in case 3 (Figure 1B). On both Ig heavy and light chain gene PCR analysis of microdissected KSHV-positive cell aggregates, an oligoclonal pattern was observed in case 1 and a polyclonal pattern 
Figure 1. Analysis of KSHV-associated GLD. (A) Histologic and immunophenotypic features of KSHV-associated GLD in case 1: The germinal centers are replaced by large cells with a moderate amount of amphophilic cytoplasm and a large vesicular nucleus containing 1 or 2 prominent nucleoli. These large cells coalesce and form confluent aggregates (panels i-ii, hematoxylin-eosin staining). They express high levels of cytoplasmic Ig (monotypic $\lg \lambda, \lg \mathrm{M} / \mathrm{D}$ ) and are therefore termed plasmablasts (iii-vi). Plasmablasts are positive for both KSHV (vii) and EBV (viii), and most of them express vIL-6 (ix). CD21 staining shows that KSHV-positive cells occur within meshworks of follicular dendritic cells $(\mathrm{x})$. Original magnification i, $\times 40$; ii-iv, $\times 600$; vii- $x, \times 400$. (B) Clonality analysis of KSHV-associated GLD in case 1: FR3-J $\mathrm{J}_{\mathrm{H}}$ PCR analysis of DNA samples from whole tissue sections shows a weak dominant band in a polyclonal background. FR2-J $J_{H}$ PCR analysis of microdissected KSHV-positive foci ( $A 1$ and $A 2$ from case 1 ) shows an oligoclonal pattern.
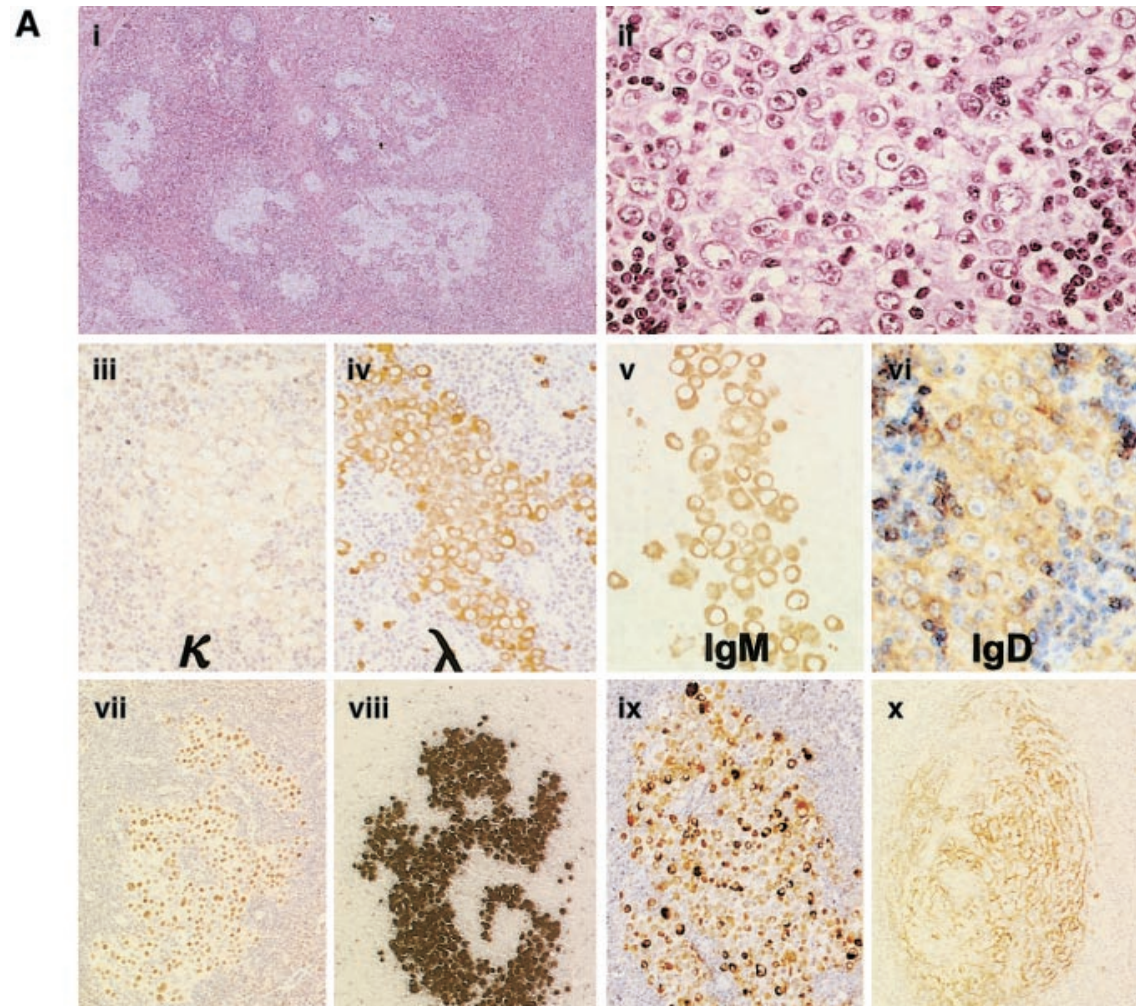

KSHV-LAN-1
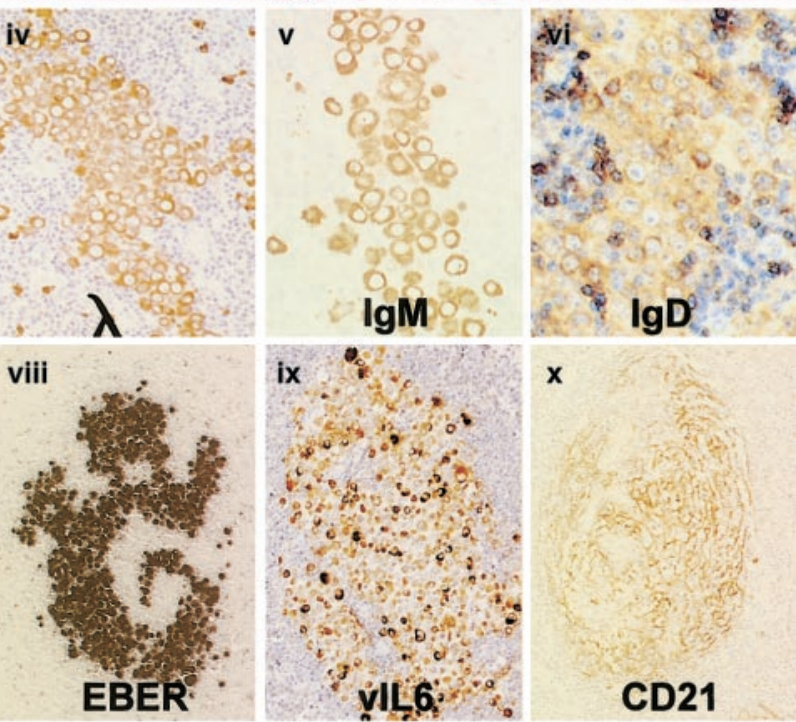

$\mathbf{X}$

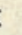

B

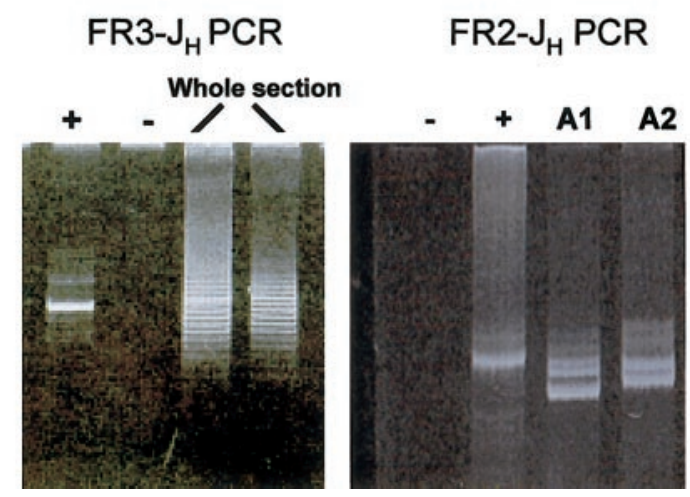

was observed in case 3 (Figure 1A). Thus, despite being monotypic in terms of $\mathrm{Ig}$ light chain expression, these KSHV-positive plasmablasts are genotypically polyclonal. PCR analysis of case 2 failed because of poor DNA quality.

To understand the cell of origin of KSHV-positive plasmablasts, the microdissected KSHV-positive cells were subjected to FR2- $\mathrm{J}_{\mathrm{H}} \mathrm{PCR}$ to

Table 2. PCR and sequence analysis of the rearranged IgH gene of KSHVpositive foci in case 1

\begin{tabular}{lccc}
\hline $\begin{array}{c}\text { KSHV-positive } \\
\text { foci }\end{array}$ & No. of clones & $\begin{array}{c}\text { Clones with } \\
\text { identical } \mathrm{V}_{\mathrm{H}} \\
\text { and CDR3 }\end{array}$ & Mutation in $\mathrm{V}_{\mathrm{H}}$ \\
\hline Focus 1 & 12 & 4 (DP77) & $5 \mathrm{R}, 3 \mathrm{~s}$ \\
& & 7 (DP88) & $2 \mathrm{R}, 2 \mathrm{~s}$ \\
Focus 2 & 1 (Yac7) & $4 \mathrm{R}$ \\
& 4 & 3 (DP58) & $2 \mathrm{R}$ \\
& 1 (DP63) & $4 \mathrm{R}, 2 \mathrm{~s}$ \\
\hline
\end{tabular}

$\mathrm{R}$ indicates replacement mutation; s, silent mutation. analyze somatic mutation of the rearranged $\mathrm{V}_{\mathrm{H}}$ gene. Successful PCR was achieved only in case 1 and showed 2 to 3 dominant bands. Cloning and sequencing of the PCR products confirmed the presence of oligoclonal B cells in each of the 2 foci examined and showed that different foci contained distinct clones despite being from the same tissue section and showing identical light chain restriction (Table 2). Furthermore, the rearranged $\mathrm{V}_{\mathrm{H}}$ region in all clones harbored somatic hypermutation, and clone DP88 from focus 1 showed intraclonal variation. Thus, although the KSHV-positive plasmablasts in this case express both $\operatorname{IgM}$ and $\operatorname{IgD}$, they most likely originated from germinal center B cells. This may represent a general feature of this lymphoma entity because case 2 expressed $\operatorname{IgA}$, indicating the plasmablasts had undergone switch recombination, which occurs after somatic mutation during the germinal center reaction.

Based on the above findings, we propose calling this lymphoproliferative disorder "KSHV-associated germinotropic lymphoproliferative disorder" (GLD). We selected this term because the 
Table 3. Comparison of KSHV-associated lymphoproliferative disorders

\begin{tabular}{|c|c|c|c|}
\hline & PEL & MCD and associated plasmablastic lymphoma & GLD \\
\hline Clinical presentation & $\begin{array}{l}\text { In immunodeficient patients, with systemic } \\
\text { symptoms, poor prognosis }\end{array}$ & $\begin{array}{l}\text { Predominantly in immunodeficient patients, } \\
\text { with systemic symptoms, poor prognosis }\end{array}$ & $\begin{array}{l}\text { In immunocompetent patients with localized } \\
\text { lymphadenopathy, favorable response } \\
\text { to therapy }\end{array}$ \\
\hline Sites & Body cavities, extranodal sites & Lymph nodes, spleen & Lymph nodes \\
\hline Morphology & $\begin{array}{l}\text { Immunoblasts with pleomorphic nuclei and } \\
\text { abundant plasmacytoid cytoplasm }\end{array}$ & $\begin{array}{l}\text { Plasmablasts, preferentially residing in the } \\
\text { mantle zone }\end{array}$ & $\begin{array}{l}\text { Plasmablasts, preferentially invading } \\
\text { germinal centers }\end{array}$ \\
\hline EBV & $\begin{array}{l}\text { Present in HIV-associated patients; } \\
\text { absent in HIV-negative patients }\end{array}$ & Negative & Positive \\
\hline Cytoplasmic Ig expression & Absent & High, always IgM & High, any heavy chain \\
\hline Ig light chain & Monotypic $\kappa$ or $\lambda$ mRNA & Monotypic $\lambda$ & Monotypic к or $\lambda$ \\
\hline CD30 & Positive & Weakly positive & Variable \\
\hline B-cell antigens & Absent & Weak or absent & Absent \\
\hline Mutation in Ig genes & Mutated in most & Absent & Mutated \\
\hline Cellular origin & Germinal center or postgerminal center B cells & Naive $\lg M \lambda$ expressing $B$ cells & Germinal center B cells \\
\hline
\end{tabular}

lymphoproliferation is polyclonal and individual KSHV-positive foci have potential to develop into monoclonal microlymphoma or even frank lymphoma, reminiscent of EBV-associated posttransplantation lymphoproliferative disorder ${ }^{12}$ and KSHV-related MCD. ${ }^{6,7}$ Lymphoma with marked tropism for germinal centers has been previously described in 3 cases of large B-cell lymphoma of the mediastinum. ${ }^{13}$ These lymphomas show similar clinical presentation and histologic features to those of KSHV-associated GLD but express CD20 and are therefore unlikely to be KSHV-associated GLD, although KSHV and EBV infection were not investigated. ${ }^{13}$

There are similarities as well as important differences between KSHV-associated GLD, PEL, and MCD-associated plasmablastic lymphoma (Table 3). KSHV-associated GLD occurs in immunocompetent individuals, presents as localized lymphadenopathy, and responds favorably to therapy. In contrast, PEL and MCD predominantly occur in immunodeficient patients, commonly pursue an aggressive clinical course, and respond poorly to current treatments. KSHV-associated GLD differs from MCD in that the plasmablasts are coinfected by EBV, may express any heavy or light chain, preferentially invade germinal centers, and harbor mutated Ig gene.

Although the exact role of viral infection in the pathogenesis of $\mathrm{KSHV}$-associated GLD is unclear, it is noteworthy that vIL-6 is expressed by most of the KSHV-positive cells, which is much higher than that in PEL and KSHV-associated MCD (10\%$20 \%){ }^{7,14}$ Activation of IL-6 receptor signaling through vIL-6 and human IL-6 may play an important role in this disease as in PEL and KSHV-associated MCD. ${ }^{7,15,16}$ Nonetheless, the pathogenic potential seems to be constrained by a competent immune system. Despite the coinfection by EBV and KSHV, the GLD presents as a localized disease and responds favorably to conventional therapy.

\section{References}

1. Sharp TV, Boshoff C. Kaposi's sarcoma-associated herpesvirus: from cell biology to pathogenesis. IUBMB Life. 2000;49:97-104.

2. Cesarman E, Knowles DM. The role of Kaposi's sarcoma-associated herpesvirus (KSHV/HHV-8) in lymphoproliferative diseases. Semin Cancer Biol. 1999;9:165-174.

3. Nador RG, Cesarman E, Chadburn A, et al. Primary effusion lymphoma: a distinct clinicopathologic entity associated with the Kaposi's sarcomaassociated herpes virus. Blood. 1996;88:645656.

4. Gaidano G, Gloghini A, Gattei V, et al. Association of Kaposi's sarcoma-associated herpesviruspositive primary effusion lymphoma with expression of the CD138/syndecan-1 antigen. Blood. 1997;90:4894-4900.

5. Matolcsy A, Nador RG, Cesarman E, Knowles DM. Immunoglobulin VH gene mutational analysis suggests that primary effusion lymphomas derive from different stages of $B$ cell maturation. Am J Pathol. 1998;153:1609-1614.

6. Dupin N, Diss TL, Kellam P, et al. HHV-8 is associated with a plasmablastic variant of Castleman disease that is linked to HHV-8-positive plasmablastic lymphoma. Blood. 2000;95:1406-1412.
7. Du MQ, Liu H, Diss TC, et al. Kaposi sarcomaassociated herpesvirus infects monotypic (IgM) but polyclonal naive B-cells in Castleman disease and associated lymphoproliferative disorders. Blood. 2000;97:2130-2136.

8. Oksenhendler E, Boulanger E, Galicier L, et al. High incidence of Kaposi sarcoma-associated herpesvirus (KSHV/HHV8)-related non-Hodgkin lymphoma in patients with HIV infection and multicentric Castleman disease. Blood. 2002;99: 2331-2336.

9. Pan LX, Diss TC, Peng HZ, Isaacson PG. Clonality analysis of defined B-cell populations in archival tissue sections using microdissection and the polymerase chain reaction. Histopathology. 1994; 24:323-327.

10. Diss TC, Pan LX, Peng HZ, Wotherspoon AC, Isaacson PG. Sources of DNA for detecting $B$ cell monoclonality using PCR. J Clin Pathol. 1994;47: 493-496.

11. Pan LX, Ramani $P$, Diss TC, Liang JN, Isaacson $P G$. Epstein-Barr virus associated lymphoproliferative disorder with fatal involvement of the gastrointestinal tract in an infant. J Clin Pathol. 1995; 48:390-392.

12. Knowles DM, Cesarman E, Chadburn A, et al.
Correlative morphologic and molecular genetic analysis demonstrates three distinct categories of posttransplantation lymphoproliferative disorders. Blood. 1995:85:552-565.

13. Suster S. Large cell lymphoma of the mediastinum with marked tropism for germinal centers. Cancer. 1992;69:2910-2916.

14. Parravicini $\mathrm{C}$, Chandran $\mathrm{B}$, Corbellino $\mathrm{M}$, et al. Differential viral protein expression in Kaposi's sarcoma-associated herpesvirus-infected diseases: Kaposi's sarcoma, primary effusion lymphoma, and multicentric Castleman's disease. Am J Pathol. 2000;156:743-749.

15. Jones KD, Aoki $Y$, Chang $Y$, et al. Involvement of interleukin-10 (IL-10) and viral IL-6 in the spontaneous growth of Kaposi's sarcoma herpesvirusassociated infected primary effusion lymphoma cells. Blood. 1999:94:2871-2879.

16. Oksenhendler E, Carcelain G, Aoki Y, et al. High levels of human herpesvirus 8 viral load, human interleukin- 6 , interleukin- 10 and $C$ reactive protein correlate with exacerbation of multicentric Castleman disease in HIV-infected patients. Blood. 2000;96:2069-2073. 